Transportation Research Forum

A New Approach for Allocating Highway Costs

Author(s): Feng Hong, Jorge A. Prozzi, and Jolanda Prozzi

Source: Journal of the Transportation Research Forum, Vol. 46, No. 2 (Summer 2007), pp. 5-19

Published by: Transportation Research Forum

Stable URL: http://www.trforum.org/journal

The Transportation Research Forum, founded in 1958, is an independent, nonprofit organization of transportation professionals who conduct, use, and benefit from research. Its purpose is to provide an impartial meeting ground for carriers, shippers, government officials, consultants, university researchers, suppliers, and others seeking exchange of information and ideas related to both passenger and freight transportation. More information on the Transportation Research Forum can be found on the Web at www.trforum.org. 


\title{
A NEW APPROACH FOR ALLOCATING HIGHWAY COSTS
}

\author{
by Feng Hong, Jorge A. Prozzi, and Jolanda Prozzi
}

The allocation of highway costs is constantly debated among legislatures, highway agencies, and highway users as it directly relates to concerns about equity in terms of cost responsibility and actual user charges. One of the major challenges in highway cost allocation stems from the need to estimate pavement damage by different vehicle classes. Normally, the calculation of damage caused by heavy vehicles to the highway infrastructure utilizes the concept of Equivalent Single Axle Load (ESAL). This concept was empirically established after the American Association of State Highway Officials America (AASHO) Road Test almost half a century ago. Although the ESAL concept is widely used in pavement design, it has a number of shortcomings when applied for the estimation of pavement damage by different vehicle classes. Some of these limitations include: failure to account for specific infrastructure and environmental conditions, disregard of the differences in traffic configurations and composition, and the inability to capture different distress types. This leads to a fairly inaccurate and generic estimation of pavement damage by vehicle class.

This paper proposes an innovative and more rational highway cost allocation approach based on the recently completed guide for the "Mechanistic-Empirical Design Guide of New and Rehabilitated Pavement Structures" developed under the National Cooperative Highway Research Program (NCHRP) Project 1-37A. The Guide accounts for all factors that contribute to pavement deterioration, thereby addressing the shortcomings of an ESAL-based analysis listed earlier. Estimates for pavement damage attributable to each vehicle class can thus be accurately simulated. For the purposes of this study, traffic data collected at a weigh-in-motion station in Texas were used to estimate the highway cost shares of different vehicle classes, given different pavement structural capacities.

\section{INTRODUCTION}

Almost since the designation of the U.S. highway system more than half a century ago, highway cost allocation (HCA) has been debated among interest groups, including state and federal legislators, highway agencies, and highway users. The objective of HCA studies has been to determine and assign a rational and equitable cost share (e.g., charge) to different vehicle classes. The motivation for allocating cost shares to the different vehicle classes is because their "consumption" of the highway differs because of their different sizes, weights, and volumes. Allocating a cost share involves a series of complex factors, such as traffic characteristics, highway structural and material properties, and environmental considerations.

Because it is inherently difficult to allocate highway costs among vehicle classes, there is no unambiguous method available for conducting HCA despite the large number of studies on this topic. Many of these studies have been updated periodically at both the state and federal levels as technologies (e.g., for collecting data) and cost allocation methods per se evolved. At the state level, it is essential for the state government to compare the fees paid and costs incurred by different vehicle classes to determine the magnitude of the subsidies, if any, to individual vehicle classes (FHWA 1997). For this reason, many states have embarked on their own HCA studies, including Arizona, California, Georgia, Indiana, Kentucky, Maryland, Texas, Oregon, Wyoming, and Wisconsin (Fwa and Sinha 1985; Luskin et al. 2001).

Based on the collection of HCA studies, the Federal Highway Administration (FHWA) published a document that contains a framework and methods to aid with cost estimation (FHWA 
1982). Eventually, the 1982 version of the HCA study was replaced with the 1997 version. The two key reasons for updating the 1982 study were:

(1) to determine the equity effects of the change in the federal highway program and user fees, and

(2) to "coordinate this effort with the concurrent U.S. Department of Transportation Comprehensive Truck Size and Weight Study” (FHWA 1997). The document also mentioned the need for more rational HCA studies in the follow-up effort.

Highway costs involve the costs associated with pavements, bridges, and other capacity-related aspects. Pavement costs are the most significant component of total highway cost, because they represent the major part of the transportation infrastructure system. Pavement costs can be further divided into: construction costs and maintenance costs. Similar to most previous studies, this paper focuses on the construction cost component of pavement costs. Furthermore, as is suggested in the 1997 HCA study, pavement construction costs can be divided into load-related costs and non-load related costs. The former applies mainly to commercial trucks, while the latter applies to all vehicle classes. This paper focuses on the load-related costs as it is relatively more difficult to estimate (Castano-Pardo and Garcia-Diaz 1995).

The objective of this study is to allocate the construction cost share among different (truck) vehicle classes based on their individual contribution to the expected damage to pavements. The next section provides background information on existing HCA methods. The third section discusses the concept of Equivalent Single Axle Load (ESAL) as it is widely used in most of the existing HCA methods. The fourth section provides an overview of the recently developed mechanistic-empirical design guide, which is a key element of the new method for HCA proposed in this paper. The fifth section presents a case study in which the proposed method was tested with actual traffic data collected in Texas before concluding with some major findings and summaries.

\section{EXISTING HIGHWAY COST ALLOCATION METHODS}

There are numerous approaches for undertaking HCA, which differ mainly in terms of theoretical implications and practical applicability (Truck Research Institute 1990). The best-known approaches are incremental and proportional methods (Castano-Pardo and Garcia-Diaz 1995). The incremental method and more recently, the modified incremental method, are the most widely applied. In the traditional incremental method, vehicle classes are added to a base pavement subsquentially. The incremental pavement thickness added due to the increased axle loading from the specific vehicle class can thus be determined step-by-step. The American Association of State Highway and Transportation Officials (AASHTO) pavement design equations are central in this calculation process. However, it can be shown that a difference in the order to which vehicle classes are added produce significantly different results. The weakness of this method originates from the non-linear relationship between pavement thickness and the associated allowable traffic as implied by the AASHTO equations and presented by Fwa and Sinha (1985). To address this, several modified incremental methods were proposed. For example, the FHWA's 1982 HCA approach suggested dividing the individual vehicle classes into an equal number of sub-groups. The traffic for incremental thickness calculation is applied in a reverse order from the traditional incremental method (FHWA 1982). In other words, the savings in pavement thickness can be obtained by removing sub-groups of vehicles from the entire traffic flow step-by-step. The share of thickness saved at each step for each vehicle class is estimated through its sub-group's contribution in terms of ESALs, which is determined via the AASHTO equations. Fwa and Sinha (1985) also proposed a thickness incremental method aiming to eliminate the need for iterated computation of ESALs required by the previous method.

The proportional method, on the other hand, is widely applied in HCA due to its ease of application. The cost is allocated among vehicle classes based on some measure or allocator, including Vehicle-Miles-Travel (VMT) and ESALs. For example, in the 1997 FHWA's HCA study, 
pavement construction cost consists of two parts: the non load-related portion and the load-related portion. ESALs are used to allocate the load-related costs among the vehicle classes.

Finally, optimization or programming techniques have been adopted to solve the HCA problem. Villarreal-Cavazos and Garcia-Diaz (1985) devised the so-called Generalized Method based on the theory of cooperative game. Linear programming was utilized for allocating the costs among vehicle classes. Castano-Pardo and Garcia-Diaz (1995) used non-atomic game theory to estimate class-based vehicle cost by regarding each vehicle passage on the road as a player in the game. In both references, ESALs are included as decision variables.

A review of the existing literature revealed that traffic load is one of the key factors in allocating costs among vehicle classes because a pavement is designed to sustain traffic and it deteriorates under the combined impact of traffic load and the environment (HRB 1962; FHWA 1997; Huang 2003). Given that all of the aforementioned approaches accounts for traffic load in terms of ESALs, the concept and implications of using ESALs need to be discussed.

\section{DISCUSSION ON ESAL}

The ESAL concept is the cornerstone of modern pavement design. ESAL is also a key component in the current AASHTO pavement design guide (1993). It is used to convert an axle load with a different configuration and weight into its equivalent number of standard axle loads (18-kip or 18,000 pounds single axle load). The ESAL was originally developed based on the analysis of the American Association of State Highway Officials America (AASHO) Road Test results, which was motivated to facilitate cost allocation among vehicles (HRB 1962). It should be noted that the equivalence is established in terms of the effects of the various axle loads and configurations on the loss of serviceability of the pavement structure. The number of ESALs associated with the number of repetitions of a particular axle load on a pavement can be calculated through the following equation (HRB 1962):

(1) $E S A L s=n \times L E F$

Where, $n$ : number of repetitions for a given axle load; and

$L E F$ : load equivalent factor.

(2) $L E F=\frac{W_{18}}{W_{x}}$

Where, $W_{18}$ : number of 18-kip single-axle load applications to reach a given serviceability

$W_{x}$ : number of x-kip axle load applications to reach the same serviceability.

$W_{18} / W_{x}$ can be obtained from the following equation (using flexible pavement as an example) (AASHTO 1993):

(3) $\log \left(W_{x} / W_{18}\right)=4.79 \log (18+1)-4.79 \log \left(L_{x}+L_{2}\right)+4.33 \log L_{2}+G_{t} / \beta_{x}-G_{t} / \beta_{18}$

(4) $G_{t}=\log \left(\frac{4.2-p_{t}}{4.2-1.5}\right)$

(5) $\beta_{x}=0.40+\frac{0.081\left(L_{x}+L_{2}\right)^{3.23}}{(S N+1)^{5.19} L_{2}^{3.23}}$ 
Allocating Highway Costs

Where, $L_{x}$ : $\quad$ the load in kip for a given axle;

$L_{2}$ : $\quad$ the axle code, 1 for single axle, 2 for tandem axle, and 3 for tridem axle;

$S N$ : the structural number, which is related to pavement thickness, material, and drainage; and

$p_{t}: \quad$ is a level of serviceability considered as pavement failure.

It is shown in the above equations that LEF (and thus ESALs) is a function of a number of variables, including pavement structure and material, axle configurations, and serviceability upon pavement failure, among others. It is important to note that some of these variables have changed since the AASHO Road Test, which took place around 50 years ago. For example, pavement materials, particularly asphalt material, have evolved significantly over the last several decades. New materials, such as modified asphalt binders, have emerged, leading to asphalt mixture improvements with more desirable road-use properties. Also, the Superpave mixture design method developed in the 1990s, directed asphalt mixture design closer to field construction conditions. Axle configurations have also changed since the AASHO Road Test. During the AASHO Road Test, only single and tandem axles were tested. Since then, tridem and quadruple axles have emerged due to demands from the rapidly growing trucking industry. Tire configurations have changed from bias-ply to radial-ply in order to improve the load-carrying capacity, which, in turn, would impose different damage on pavements (Machemehl et al. 2005). Tire inflation pressures have increased from an average of 80 pounds per square inch (psi) to $100 \mathrm{psi}$ or higher. In addition to the abovementioned physical changes that affect the determination of the measure of traffic loading and pavement impacts, three other equally important concerns deserve further discussion:

- The first concerns the duration of the AASHO Road Test. The fact that the AASHO Road Test was an accelerated pavement test, which lasted two years, cast doubts on its capacity to fully capture a pavement's long term performance. It should be borne in mind that flexible pavement structures are usually designed to sustain traffic and the environment for 20 to 30 years.

- The second concerns the generalization of the underlying design equation (AASHTO 93), which was developed based on a road test in Illinois. Whether it applies to other areas (e.g., the southern states) with environmental conditions markedly different from Illinois has remained questionable.

- Lastly, the abovementioned design equation suffers from model specification and estimation flaws such as using step-wise estimation and ignoring unobserved events (Small and Winston 1989). This also resulted in a bias in estimating LEF.

\section{MECHANISTIC-EMPIRICAL PAVEMENT DESIGN GUIDE}

To address the aforementioned concerns in the traditional pavement design method, the National Cooperative Highway Research Program (NCHRP) funded an ambitious research project aimed at developing a guide for the "Mechanistic-Empirical Design of New and Rehabilitated Pavement Structures,” hereafter referred to as the M-E Design Guide (NCHRP 2006). The research resulted in the most comprehensive pavement analysis tool developed to date. The M-E Design Guide is available in the form of a computer program at TRB's website: www.trb.org/mepdg. Figure 1 illustrates the software's general framework, which includes input, analysis, and output blocks. 
Figure 1: M-E Design Guide Framework

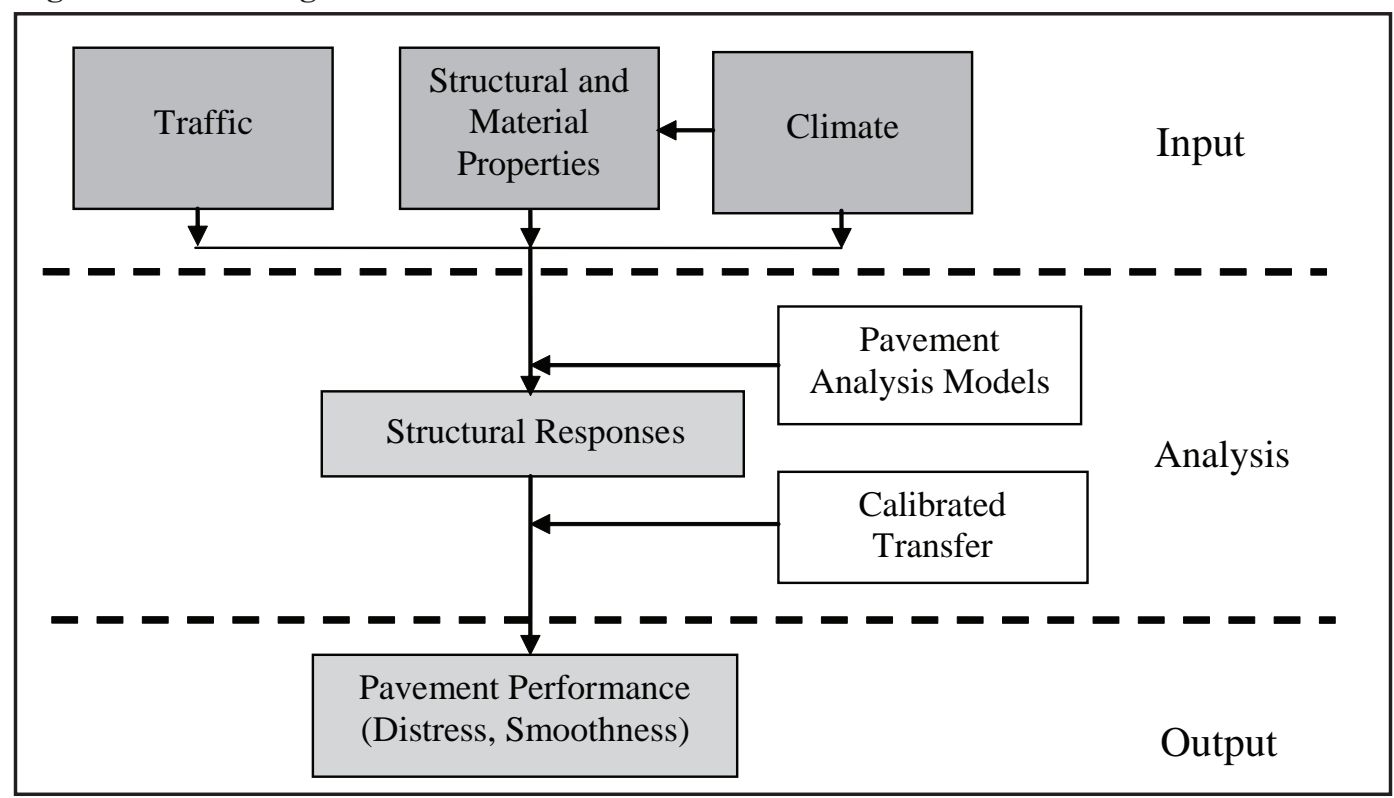

An extensive amount of information pertaining to pavement performance is required as the input parameters, including very detailed traffic volume and load data, pavement structural and material properties, and environmental conditions. The environmental information can be generated directly by selecting weather stations from a database, which covers hundreds of locations in the U.S. Traffic data are mainly composed of volume and load information. For traffic volume, both short- and longterm characteristics are required in the M-E Design Guide (Prozzi and Hong 2006). For traffic load, instead of ESALs, real axle loads - i.e., axle load distribution (referred to as axle load spectra) - are used to capture actual traffic characteristics more closely. Then, a mechanistic analysis is carried out to generate pavement responses under the joint effect of the environment and traffic. These responses are finally correlated with pavement performance indicators (e.g., cracking, rutting, and roughness) using calibrated transfer functions (i.e., empirical equations to relate pavement response to performance). These features of the M-E Design Guide provide a more accurate methodology to determine pavement deterioration under actual pavement service conditions, because pavement performance can be estimated in a more realistic and comprehensive manner than with the traditional empirical approach. It also allows for the examination of pavement damage by different vehicle classes. The latter is discussed subsequently.

\section{PROPOSED APPROACH TO HIGHWAY COST ALLOCATION}

This paper proposes an innovative approach for estimating the pavement damage share by different classes of trucks. Before discussing this new approach, however, traffic classification and the main characteristics of axle load given the individual vehicle classes are worth highlighting.

According to the Traffic Monitoring Guide, vehicles can be categorized into 13 classes (FHWA 2001). Among them, trucks (including buses) constitute Class 4 to Class 13, as is shown in Figure 2. However, the proposed method in this paper can be applied to any other classification scheme. Thus, choosing this 13-class based classification does not exclude other vehicle classification schemes.

The vast majority of trucks exhibit four types of axle configurations: single, tandem, tridem, and quads axles. The axles in the different truck classes may be loaded with different weights. However, each passing axle load can automatically be collected by weigh-in-motion (WIM) equipment to obtain a sample of axle loads for each axle type for the individual truck class. From the axle load 
Allocating Highway Costs

distributions (also referred to as axle load spectra) it has been observed that the individual vehicle classes feature one mode or several modes. Figures 3 and 4 provide examples of single and tandem axle load spectra obtained at a WIM station (labeled D516) in Texas. The x-axis represents axle load weight and the y-axis represents the normalized frequency. This WIM station is located on Interstate Highway 35 (IH-35) outside San Antonio. The detailed statistical characteristics of the axle load spectra were thoroughly explored during a previous study (Prozzi et al. 2006). In addition, it is important to point out that axle load data collected by WIM equipment can be subject to two types of measurement errors: random error, which is due to the equipment's intrinsic properties, and systematic error, which is due to external factors such as roadway and environmental conditions. However, it has been found that given well-calibrated conditions the effect of measurement error, mainly from random error, does not have a significant impact on load-pavement impact estimation (Prozzi and Hong 2007). In this example, the traffic data can be regarded "good quality" since the WIM scale was frequently calibrated by Texas Department of Transportation (TxDOT) personnel.

Figure 2: Vehicle Classification Scheme (FHWA, TMG2001)

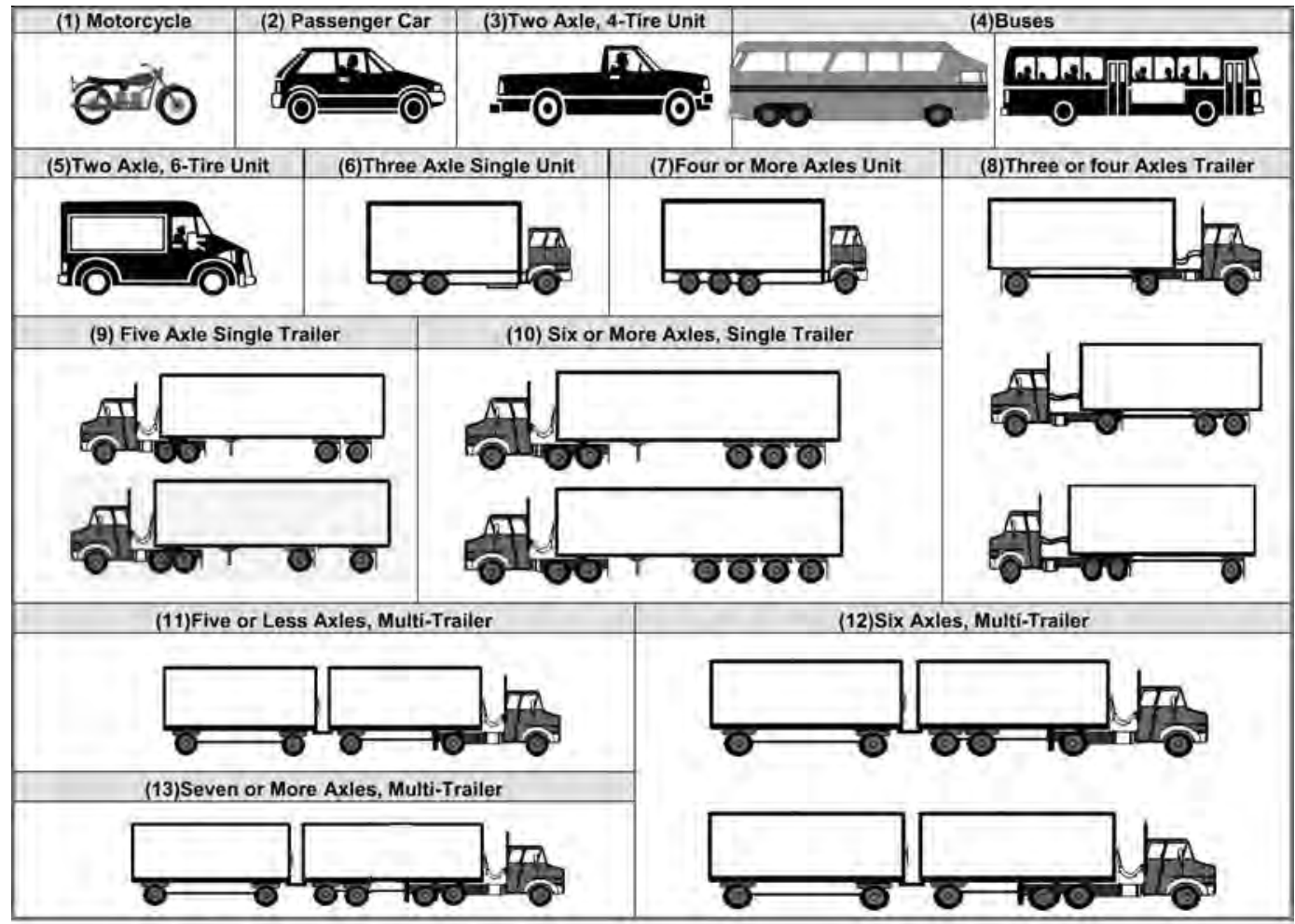


Figure 3: Single Axle Load Spectra

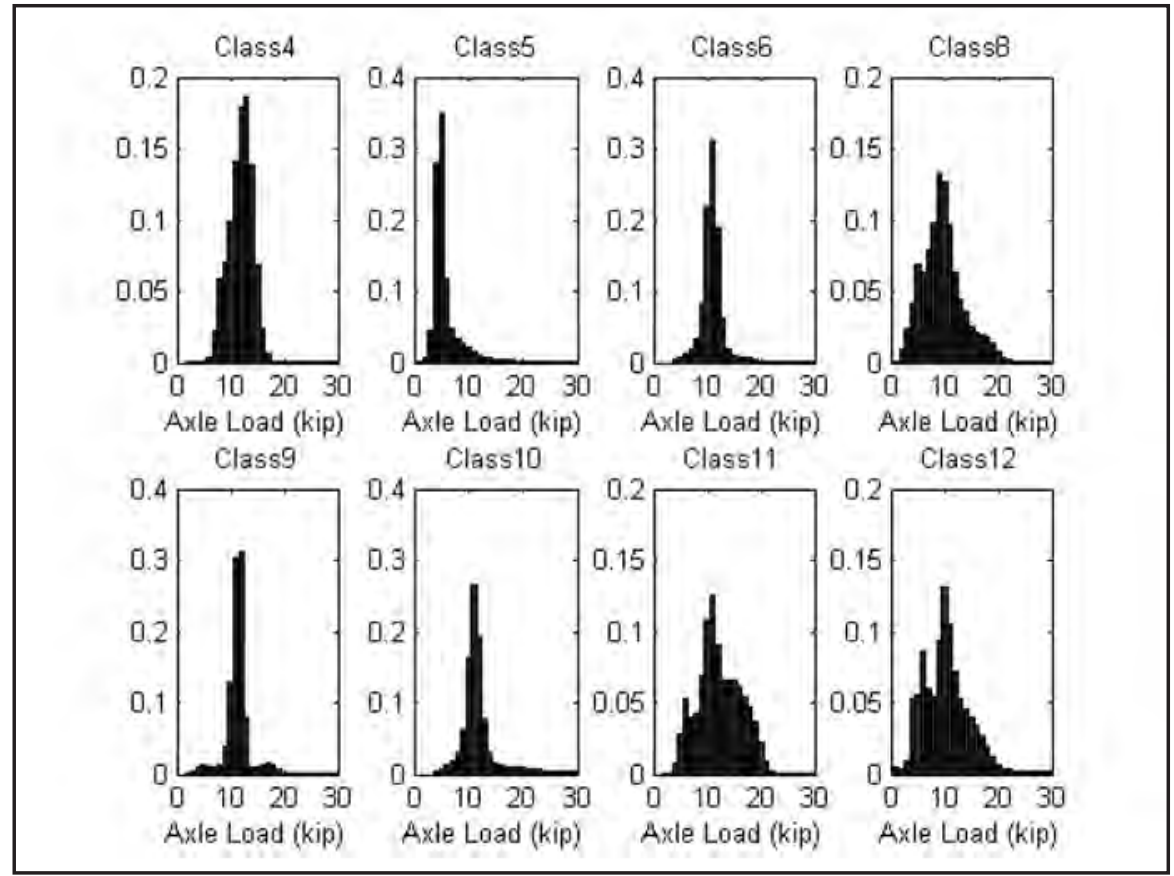

Figure 4: Tandem Axle Load Spectra

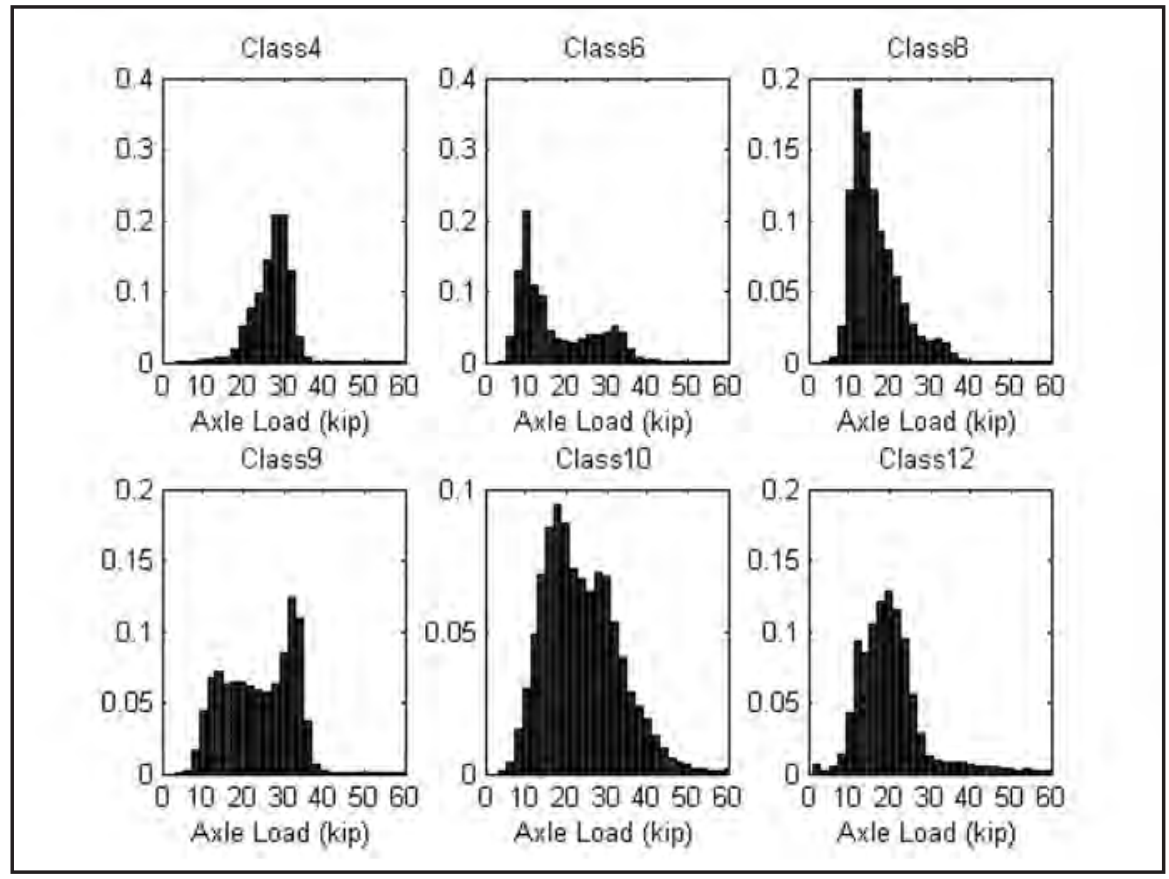

Since each truck class is characterized by a particular axle load distribution, the pavement damage imposed by each truck class may differ. The damage imposed by a particular truck class can be obtained as follows. First, for a given pavement and given period of time (e.g., a design life of 20 years), the maximum (allowable) number of repetitions for a particular truck class can be obtained 
from the mechanistic-empirical approach proposed by the M-E Guide (via its software). Through the Guide's software, it is straightforward to obtain the number of repetitions until pavement failure at the end of design life. This number of repetitions of a particular truck class provides a measure of pavement damage from a vehicle's perspective. The higher the number of repetitions, the less damage by each pass of that vehicle type is imposed on the pavement. It is important to note that all cases pertain to the same pavement, environment and duration, and pavement failure criterion. Second, a comparison of the maximum number of repetitions to failure from different vehicle types provides the relative damage among those classes. Assuming that the load-related costs associated with each truck type is proportional to its contribution to pavement wear (reflected through pavement damage), the cost share among truck classes can be calculated as being equal to that truck type's relative pavement damage proportion. The detailed steps to obtain the relative damage are as follows:

1. Prepare the input information, including pavement structure, material, environment, and traffic (particularly axle load distributions for each truck class).

2. Select failure criterion (which represents pavement performance at the end of a given service life) from which the maximum allowable number of repetitions of a given vehicle type can be obtained.

3. For each truck class with its axle load spectra, calculate the maximum number of repetitions until pavement failure at the end of the design life (such as 20 years) of the pavement, denoted as $N_{i} . i=4, \ldots 13$. Similarly, for the mixed traffic flow with its axle load spectra, the number of repetitions until pavement failure at the end of its design life is also obtained as the reference, denoted as $N_{M i x}$.

4. Define the inverse of the ratio between the allowable volumes by each truck class to the mixed traffic flow as the relative average damage by one pass of that vehicle class. Obtain the relative damage by each pass for each vehicle class as,

(6) $R_{i}=\left(N_{i} / N_{\text {Mix }}\right)^{-1}$

Where, $N_{i}$ : the maximum number of repetitions until pavement failure at the end of the design life for each truck class; and

$N_{M i x}$ : the number of repetitions until pavement failure for the mixed traffic flow. $N_{M i x}$ is an output from the M-E Design Guide software.

5. Obtain the cost share for each truck class as,

(7) $C_{i}=\left(V_{i} R_{i}\right) / \sum_{j=4}^{13}\left(V_{j} R_{j}\right)$

Where, $V_{i}$ : volume of Class $i$ as a percentage of total truck traffic flow.

To facilitate the understanding of the proposed approach for allocating the cost share among truck classes, a case study with actual traffic data is provided in the next section.

\section{CASE STUDY}

\section{Traffic Data Description}

Actual traffic data were collected from WIM Station D516, on IH-35, near San Antonio. The traffic data from this particular WIM station covers the period from January 1998 to March 2002. The volume percentages of the individual truck classes are shown in Figure 5. From Figure 5, it is evident that approximately $63 \%$ of the trucks are Class 9, followed by Class 5 (around 23\%). Although almost no Class 7 and 13 trucks were found in the truck flow, there is no sound reason to equate the pavement damage by these truck classes to their volume proportions since the load distributions vary significantly. Figures 3 and 4 present the detailed load distributions for single and tandem axles for all classes of trucks. The load spectra for tridem and quads were found to be negligible in the 
sample. The load distribution information shown in the figures was used for the mechanistic analysis using the M-E Design Guide for determining pavement damage by different truck classes.

Figure 5: Volume Percentages in Truck Traffic Flow

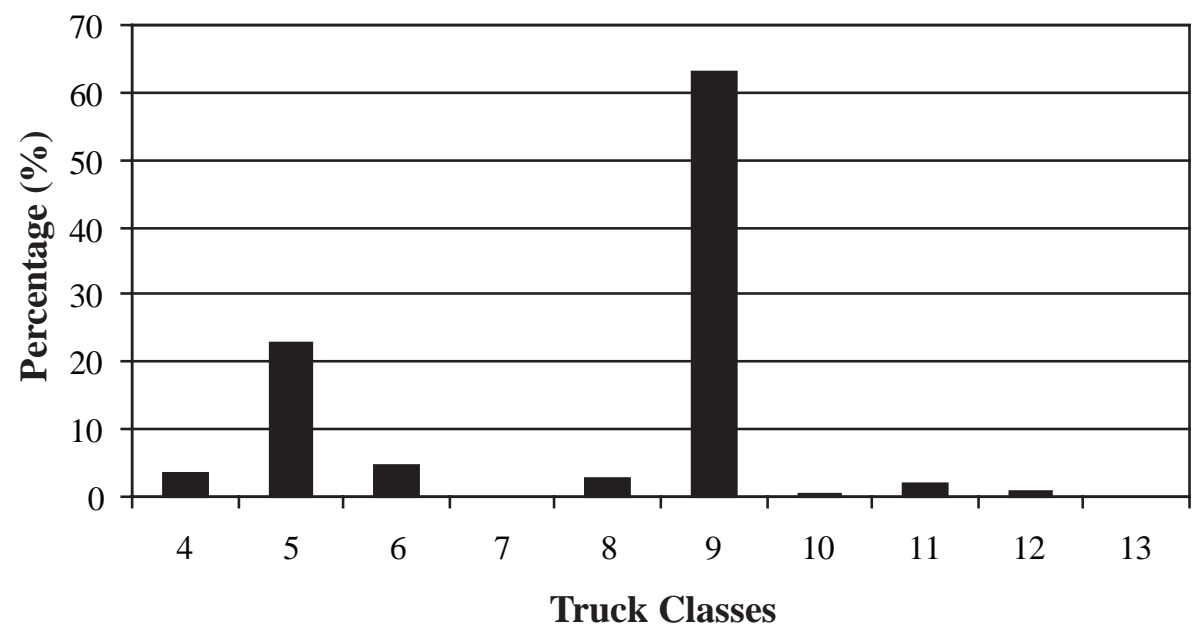

\section{Environment}

The environmental information input from the weather station nearest to the traffic data collection location (i.e., San Antonio airport) was used. A file containing the necessary climatic information for all Texas weather stations can be downloaded from the M-E Design Guide's webpage (www.trb. org/mepdg).

\section{Pavement Structure and Material}

The proposed cost allocation method can be applied to both flexible and rigid pavements. In this paper, the research focus is on the flexible pavement. A typical flexible pavement structure (i.e., three-layer pavement structure) and materials (i.e., asphalt mixture serving as surface layer, granular materials as base and subbase layers, and a silty-clay material as the subgrade) used in Texas were adopted. A series of scenarios were investigated to establish the relationship between damage share among truck classes and different pavement structures. To reduce the time (approximately 45 minutes of computer running time per case) required for the analysis due to the many possible pavement structure combinations, the thickness of the base and subbase layers were fixed at 12 inch (in.) and 6 in., respectively. An analysis was undertaken to examine the sensitivity of damage share among truck classes to surface layer thickness. The surface layer thickness is designed to accommodate different traffic levels with thicker surface layers designed for heavier traffic. For this case study, the surface layer thickness ranged from 3 in. to 8 in. with 1 in. increments. Consequently, the underlying pavements' structural numbers $(\mathrm{SN})$ vary from 3.66 to 5.86 .

\section{Pavement Performance Analysis}

Given all the inputs, pavement performance analysis was conducted using the M-E Design Guide. For each pavement structure scenario, traffic information for the individual truck classes is entered into the analysis one at a time. The only decision variable to be determined is the number of repetitions by the individual class of truck that will result in a given failure criterion at a pre- 
established design life. All the other variables remain the same. As a result, the maximum number of repetitions for the individual vehicle class (given their specific load characteristics) on the same pavement experiencing the same environment will be obtained. This provides a common basis for comparing the damage to pavement structures by different vehicle classes. As customary in Texas, pavement design life was selected to be 20 years. At the end of 20 years, the pavement thus reaches failure under a given traffic condition. For this case study, $0.5 \mathrm{in} .(12.5 \mathrm{~mm})$ of surface rutting was chosen as the failure criterion, because this criterion is widely accepted as a pavement failure criterion in the pavement community. This does not preclude selecting other failure criteria and thresholds for HCA analysis. The same approach proposed in this paper applies if a different failure criterion is specified, although it is plausible that a different criterion could lead to different relative damage ratios among truck classes.

To obtain the maximum number of repetitions for each vehicle class for the 20-year design life, an iterative process is adopted when running the M-E design guide program. If the pavement does not reach the failure threshold for a given traffic volume level by the end of 20 years, the volume input will be increased or decreased if the pavement reaches the threshold before the end of 20 years. The volume can be adjusted easily considering the output from the performance curves.

\section{Results and Discussion}

Table 1 presents the results of the maximum traffic volume for each vehicle class, as well the mixed traffic flow. The results can be interpreted as follows: for a given pavement, the truck class with the most repetitions until pavement failure imposes the least damage on the pavement by "each pass" of that vehicle class given its specific load characteristics (see Figures 3 and 4). The results from Table 1 imply that for each given pavement, Class 12 induces the most damage on a per-vehicle and per pass basis because of its smallest maximum allowable volume among all truck classes. Class 12 is followed by Classes 10, 9, and 11; while due to its largest allowable repetitions, Class 5 is the least damaging followed by Classes 8,6 , and 4 . It is thus recommended that the truck classes could be categorized into two groups of classes with Classes 12, 10, 9, and 11 comprising the "heavy" truck group and the rest comprise the "light" truck group.

Table 1: Maximum Allowable Traffic Volumes (Repetitions) of Varying Truck Classes During a 20-Year Period

\begin{tabular}{|c|c|c|c|c|c|c|c|c|c|}
\hline $\begin{array}{l}\text { Surface } \\
\text { Layer } \\
\text { Thickness } \\
\text { (in ) }\end{array}$ & $\begin{array}{c}\text { Class4 } \\
N_{4}\end{array}$ & $\begin{array}{c}\text { Class5 } \\
N_{5}\end{array}$ & $\begin{array}{c}\text { Class6 } \\
N_{6}\end{array}$ & $\begin{array}{c}\text { Class8 } \\
N_{8}\end{array}$ & $\begin{array}{c}\text { Class9 } \\
N_{9}\end{array}$ & $\begin{array}{c}\text { Class10 } \\
N_{10}\end{array}$ & $\begin{array}{c}\text { Class11 } \\
N_{11}\end{array}$ & $\begin{array}{c}\text { Class12 } \\
N_{12}\end{array}$ & $\begin{array}{c}\text { All Truck } \\
\text { Classes } \\
N_{M i x}\end{array}$ \\
\hline 3 & $2,941,900$ & $15,198,600$ & $4,350,800$ & $4,489,500$ & $1,730,100$ & $1,452,700$ & $2,233,800$ & $1,189,900$ & $2,306,800$ \\
\hline 4 & $4,088,000$ & $19,461,800$ & $6,168,500$ & $6,248,800$ & $2,430,900$ & $2,284,900$ & $3,343,400$ & $1,861,500$ & $3,394,500$ \\
\hline 5 & $5,555,300$ & $25,236,100$ & 7,957,000 & $8,526,400$ & $3,438,300$ & $3,387,200$ & $4,883,700$ & $2,642,600$ & $4,686,600$ \\
\hline 6 & $6,854,700$ & $30,798,700$ & $10,139,700$ & $10,621,500$ & $4,277,800$ & $4,409,200$ & $6,358,300$ & $3,569,700$ & $5,891,100$ \\
\hline 7 & $8,081,100$ & $36,959,900$ & $12,315,100$ & $13,059,700$ & $5,343,600$ & $5,803,500$ & $7,949,700$ & $4,416,500$ & $7,205,100$ \\
\hline 8 & $9,913,400$ & $43,756,200$ & $14,673,000$ & $15,366,500$ & $7,139,400$ & $6,445,900$ & $9,738,200$ & $5,657,500$ & $8,723,500$ \\
\hline
\end{tabular}

The underlying relationship can also be captured by calculating the relative damage by each pass of a specific truck classes. Given an individual pavement structure scenario, the relative damage on the pavement by each pass of a given truck class can be obtained by Equation (6). Through $R_{i} / \sum_{j=4}^{13} R_{j}\left(R_{i}\right.$, see equation 6), the percentage of pavement damage by each pass of different truck 
classes under different pavement structure scenarios can be calculated, as is illustrated in Figure 6. It is shown that the percentage damage among the truck classes differ when the surface layer thickness change. From Figure 6 it is evident that the share responsibility of the heavy trucks decreases as the thickness of the surface layer increases, while the light trucks' share increases. This finding supports previous research results and engineering judgment in that thinner pavement structures are more sensitive to load changes than thicker pavements.

Figure 6: Change in Per-vehicle Damage Share with Different Surface Layer Thickness
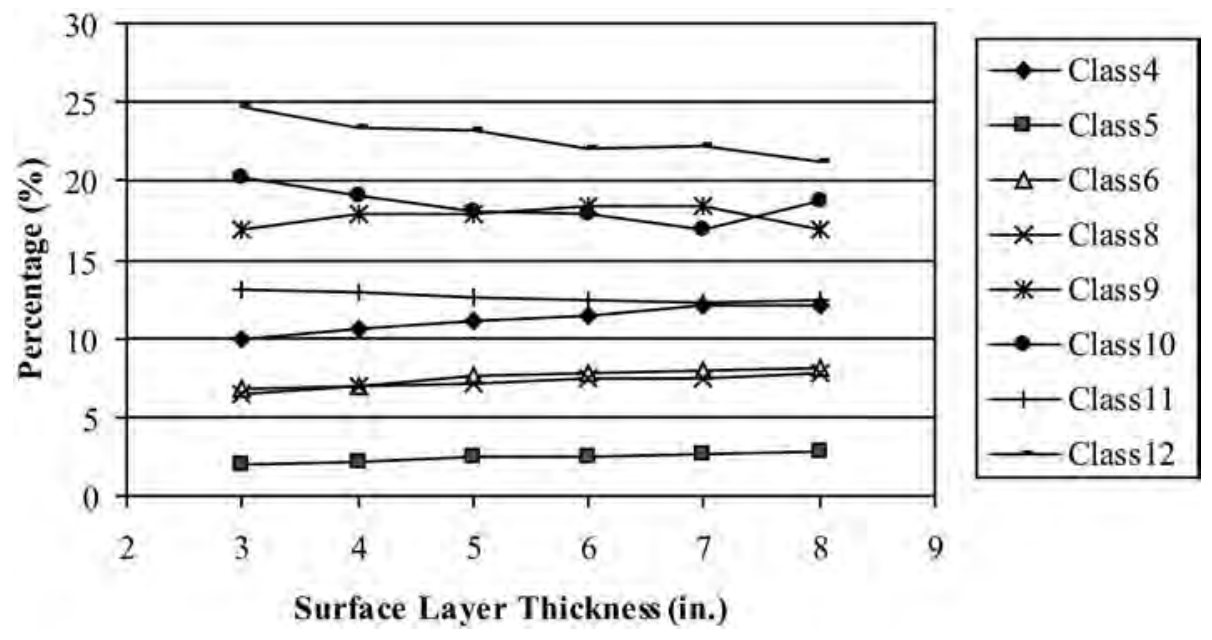

More importantly, the results presented can facilitate decision-making on class-based charges for different truck classes as a function of their load-induced damage to pavements. For example, the results suggest that each Class 9 vehicle could be charged as much as 8.8 times more than a Class 5 vehicle for the thinner pavement analyzed (corresponding to a relatively low trafficked highway), while the ratio is 6.1 times for the thicker pavement (corresponding to a relatively heavy trafficked highway).

Another critical goal of HCA is to determine the cost responsibility among vehicle classes. This requires both the consideration of the load distribution characteristics and the traffic volume associated with each vehicle class. Integrating these two components, i.e., applying Equation (7), provides the cost shares among truck classes under different pavement structure scenarios. These percentages are presented in Table 2. It is clearly shown that Class 9 dominates the cost share among trucks, accounting for more than $80 \%$ of the cost share. This high percentage results from the fact that, at the location evaluated, Class 9 vehicles represent the largest volume of trucks and carry heavier loads than most other trucks. All of the other truck classes are responsible for less than 5\% of the cost share, individually. Despite being the lightest truck class, Class 5 trucks are responsible for the second largest cost share because they accounts for the second largest volume percentage. Class 10 trucks account for the smallest cost share due mainly to low traffic volumes compared to other truck classes. It should be noted that the results presented in this section are site-specific and the methodology should be applied to several other sites to establish general trends. However, it is recommended that cost share estimation should be site-specific due to the sensitivity of pavement damage to pavement type, environmental conditions, and traffic loading characteristics. 
Allocating Highway Costs

Table 2: Cost Share Responsibilities Among Truck Classes

\begin{tabular}{|c|c|c|c|c|c|c|c|c|}
\hline $\begin{array}{c}\text { Surface Layer } \\
\text { Thickness (in.) }\end{array}$ & Class4 & Class5 & Class6 & Class8 & Class9 & Class10 & Class11 & Class12 \\
\hline 3 & $2.63 \%$ & $3.53 \%$ & $2.59 \%$ & $1.36 \%$ & $85.50 \%$ & $0.81 \%$ & $2.20 \%$ & $1.38 \%$ \\
\hline 4 & $2.66 \%$ & $3.88 \%$ & $2.56 \%$ & $1.37 \%$ & $85.50 \%$ & $0.72 \%$ & $2.07 \%$ & $1.24 \%$ \\
\hline 5 & $2.75 \%$ & $4.20 \%$ & $2.79 \%$ & $1.41 \%$ & $84.95 \%$ & $0.68 \%$ & $1.99 \%$ & $1.23 \%$ \\
\hline 6 & $2.78 \%$ & $4.29 \%$ & $2.73 \%$ & $1.41 \%$ & $85.10 \%$ & $0.65 \%$ & $1.91 \%$ & $1.13 \%$ \\
\hline 7 & $2.93 \%$ & $4.45 \%$ & $2.80 \%$ & $1.43 \%$ & $84.75 \%$ & $0.62 \%$ & $1.90 \%$ & $1.14 \%$ \\
\hline 8 & $3.14 \%$ & $4.93 \%$ & $3.08 \%$ & $1.60 \%$ & $83.32 \%$ & $0.73 \%$ & $2.03 \%$ & $1.17 \%$ \\
\hline
\end{tabular}

\section{An Extension to All-Vehicle Based Cost Allocation}

The FHWA's HCA study (1997) proposes that newly constructed highway costs are composed of two components. The first component is the load-related portion, which can be obtained through the above procedure. The second component is the non-load-related portion, or base facility cost. The FHWA's 1997 HCA study suggests a series of proportions attributable to base facility cost for different highway functional classes. For example, the percentages of base facility cost for rural highways (with flexible pavements) including interstate, other principal arterials, minor arterials, major collectors, minor collectors, and locals are 17.1, 22.5, 31.1, 38.8, 45.1, and 57.4, respectively. Base facility shares thus increase with a decrease in highway functional class. This implies that the cost share from the load-related portion decreases with an increase in highway functional class. Considering that higher-order highway classes are usually designed with stronger, thicker pavements, this supports the findings presented in this paper in that stronger pavements are less sensitive to traffic load.

The cost allocation pertaining to base facility among all vehicle classes can be obtained through passenger car equivalent (PCE) weighted VMT (FHWA 1997). Combining the latter with the cost shares pertaining to the load-related portion by truck class, will produce the final cost share for different vehicle classes.

\section{CONCLUSIONS}

This paper proposes a mechanistically-based approach for determining highway pavement construction cost allocation. Specifically, the load-related cost share among truck classes is evaluated and quantified. The recently developed M-E Pavement Design Guide was used to calculate pavement damage more accurately than the current empirical design guide. Unlike existing HCA studies, the new guide allows the quantification of all relevant variables affecting pavement deterioration. In particular, the use of axle load spectra to represent load characteristics makes pavement performance estimation more realistic. The M-E Design Guide provides a more rational approach for allocating the pavement damage share among different vehicle classes. A case study was conducted with actual traffic data obtained from a WIM station in Texas. A series of scenarios were evaluated to establish the relationship between cost share among truck classes and different pavement structures. In addition, a discussion on cost allocation among all vehicle classes was presented. The major findings presented in this paper can be summarized as follows:

1. The pavement damage by each pass of a truck varies significantly for different vehicle classes. This result suggests the need for a scientifically-based quantitative measure to determine the cost incurred by each pass of each truck type given their individual damage proportion. Based on the damage potential, Classes 12, 10, 9, and 11 are grouped into the "heavy" truck group, which has a higher damage contribution than Classes 4, 6, 8, and 5, which are grouped into the "light truck group. 
2. The damage percentage by each pass of truck varied among the truck classes for different pavement structures. Given an increase in the thickness of the pavement asphalt layer, the "heavy" truck group's damage share decreases, while the "light” truck group's share increases.

3. Class 9 trucks, the " 18 -wheelers" contribute more than $80 \%$ of the damage cost attributable to truck traffic. All the remaining truck classes' cost share is less than $5 \%$ each.

In conclusion, the approach described in this paper provides a scientific, more realistic, accurate, and easy-to-implement method for conducting cost allocation among different vehicle classes for newly constructed highway pavements. The approach accounts for different pavement types, structures, climate regions, and varying vehicle configurations. With the aid of the new M-E Design Guide, rehabilitation cost allocation can be done similarly. In terms of policy implications, the proposed approach provides an objective means to determine the equity of highway user fees, which is the ultimate goal for HCA studies.

\section{References}

American Association of State Highway and Transportation Officials (AASHTO). AASHTO Guide for Design of Pavement Structures, Washington, D.C., 1993.

Castano-Pardo, A. and A. Garcia-Diaz. "Highway Cost Allocation: An Application of the Theory of Nonatomic Games.” Transportation Research A 29(3), (1995): 187-203.

Federal Highway Administration, U.S. Department of Transportation. Final Report on the Federal Highway Cost Allocation Study, Washington, D.C., 1982.

Federal Highway Administration, U.S. Department of Transportation. 1997 Federal Highway Cost Allocation Study Final Report, Washington, D.C., 1997.

Federal Highway Administration, U.S. Department of Transportation. Traffic Monitoring Guide, Washington, D.C., 2001.

Fwa, T. F. and K. C. Sinha. "Thickness Incremental Method for Allocating Pavement Construction Costs in Highway Cost-Allocation Study.” In Transportation Research Record: Journal of the Transportation Research Board 1009, (1985): 1-7.

Highway Research Board (HRB). The AASHO Road Test, Special Report Nos. 61A through $61 G$ and 73, Washington, D.C., 1962.

Huang, Y. H. Pavement Analysis and Design. Prentice Hall, Inc., New Jersey, 2003.

Luskin, D., A. Garcia-Diaz, D. Lee, Z. Zhang, and C. M. Walton. A Framework for the Texas Highway Cost Allocation Study. Report No. 0-1801-1, Center for Transportation Research, the University of Texas at Austin, and Texas Transportation Institute, Texas A\&M University System, 2001.

Machemehl, R. B., F. Wang, and J. A. Prozzi. “Analytical Study of Effects of Truck Tire Pressure on Pavement Using Measured Tire-Pavement Contact Stress Data.” CD-ROM. Transportation Research Board, Washington, D.C., 2005.

National Cooperative Highway Research Program. Development of the 2002 Guide for the Design of New and Rehabilitated Pavement Structures: Phase II. http://www.trb.org/mepdg/. National

Cooperative Highway Research Program Research Project 1-37A, Washington, D.C. Accessed May, 2006. 
Allocating Highway Costs

Prozzi, J. A. and F. Hong. "Seasonal Time Series Models for Supporting Traffic Input Data for Mechanistic-Empirical Design Guide.” In Transportation Research Record: Journal of the Transportation Research Board 1947, (2006): 175-184.

Prozzi, J. A., F. Hong, and J. Leidy. "Optimum Statistical Characterization of WIM Data Based on Pavement Impact.” CD-ROM. Transportation Research Board, Washington, D.C., 2006.

Prozzi, J. A. and F. Hong. "Effect of Weigh-in-Motion System Measurement Errors on LoadPavement Impact Estimation.” ASCE Journal of Transportation Engineering 133 (1), (2007): 1-10.

Small, K. A. and C. Winston. Road Work: A New Highway Pricing and Investment Policy. The Bookings Institution, Washington, D.C., 1989.

Trucking Research Institute. Final Report: Rationalization of Procedures for Highway Cost Allocation. The URBAN Institute SYDEC, Inc. In association with KT Analytics, Inc. and Jack Faucett Associates, Inc., 1990.

Villarreal-Cavazos, A. and A. Garcia-Diaz. "Development and Application of New Highway Cost-Allocation Procedures.” In Transportation Research Record: Journal of the Transportation Research Board 1009, (1985): 1-7.

Feng Hong earned his Ph.D. from the University of Texas at Austin in 2007. Before coming to the United States, he received his B.S. and M.S. degrees in transportation engineering from Southeast University, China. He has been conducting research in transportation engineering and management of infrastructure systems. His current research interests include: infrastructure systems and management, life-cycle cost analysis, statistical characterization of truck traffic load, behavior and performance of highway pavements, and application of statistics and econometrics in transportation problems.

Jorge A. Prozzi joined the University of Texas in 2002. He is an assistant professor of civil engineering at the University of Texas. A native of Argentina, he received a B.S. in civil engineering from the Universidad Nacional del Sur in Bahia Blanca in 1989. He obtained his M.S. and Ph.D. degrees in civil engineering from the University of California, Berkeley.

Prozzi is a member of numerous committees of the National Academy of Sciences Transportation Research Board. His other professional or technical society memberships include the American Society for Civil Engineers, the Institute of Transportation Engineers, the International Society of Asphalt Pavements, and the Association of Asphalt Pavement Technologists. He also is a member of the Research Technical Advisory Panel for the Texas Department of Transportation.

Prozzi has authored and co-authored more than 50 publications in the areas of pavement materials and design, life-cycle cost analysis, asphalt technology, accelerated pavement testing, pavement management systems, applied probability and statistics to transportation problems, and reliability and risk analysis. His current projects include evaluation of the effects of traffic loading on transportation infrastructure performance and cost allocation, development of an improved method for designing asphalt mixes for optimum performance, development of pavement performance measures for design-build highway projects, application of pavement preservation principles for extending the performance of pavements, and optimization of pavement deterioration models for pavement management systems.

Jolanda (Pretorius) Prozzi has more than 15 years of professional and research experience in the areas of transportation economics, freight planning, and freight policy analysis. Prozzi has 
managed and collaborated on numerous Texas Department of Transportation (TXDOT) projects since joining the Center for Transportation Research in 2001. Her most recent work at the Center for Transportation Research includes researching the integration and consolidation of border freight transportation data for planning applications and the characterization of NAFTA truck loads for aiding in transportation infrastructure management. She is also developing a sketch planning cost-benefit analysis tool to calculate the societal impacts (e.g., the travel time, safety, and emissions impacts) of traditional highway investments relative to improvements in freight rail and barge infrastructure. Prozzi is estimating county-level truck data for TxDOT's Statewide Analysis Model and providing recommendations for collecting and maintaining a Texas truck travel database. Other activities include analyzing the issues surrounding passenger rail sharing freight rail infrastructure; describing the impacts of inland ports on trade flows and transportation in Texas; measuring and estimating containerized freight movements in Texas; and investigating the factors contributing to and the implications of growing truck traffic in rural Texas.

Prozzi has been the primary and contributing author of over 50 publications. She was a member of the technical advisory panel for the Texas Department of Transportation Research Management Committee on Traffic Operations (2002-2005) and the National Cooperative Highway Research Program (NCHRP) project panel for project 08-47: Policy, Planning, and Programming for Goods Movement and Freight in Small and Mid-Sized Metropolitan Areas. Prozzi is currently a member of the Transportation Research Board (TRB) Committee on Transportation Economics and is a friend of the TRB Committee on Taxation and Finance, Intermodal Freight Transport, and the TRB Task Force on Trucking Industry Research. 